\title{
Effects of Korean Red Ginseng on
} Cardiovascular Risks in Subjects with

\section{Metabolic Syndrome: a Double-blind Randomized Controlled Study}

\section{Byoung-Jin Park, Yong-Jae Lee, Hye-Ree Lee, Dong-Hyuk Jung ${ }^{1}$, Ha-Young Na, Hong-Bae Kim², Jae-Yong Shim*}

Department of Family Medicine, Yonsei University College of Medicine, Seoul; ${ }^{1}$ Department of Family Medicine, Yonsei University Wonju College of Medicine, Wonju; ${ }^{2}$ Department of Health Promotion Center, Gangnam Severance Hospital, Yonsei University College of Medicine, Seoul, Korea

Background: This study investigated the effects of Korean red ginseng (KRG) supplementation on metabolic parameters, inflammatory markers, and arterial stiffness in subjects with metabolic syndrome.

Methods: We performed a randomized, double-blind, placebo-controlled, single-center study in 60 subjects who were not taking drugs that could affect metabolic and vascular functions. Subjects were randomized into either a KRG (4.5 g/d) group or a placebo group for a 12-week study. We collected anthropometric measurements, blood for laboratory testing, and brachial-ankle pulse wave velocity (baPWV) at the initial (week 0) and final (week 12) visits.

Results: A total of 48 subjects successfully completed the study protocol. Oral administration of KRG did not significantly affect blood pressure, oxidative or inflammatory markers, or baPWV.

Conclusion: We found no evidence that KRG had an effect on blood pressure, lipid profile, oxidized low density lipoprotein, fasting blood glucose, or arterial stiffness in subjects with metabolic syndrome. These findings warrant subsequent longer-term prospective clinical investigations with a larger population.

Trial Registration: ClinicalTrials.gov Identifier: NCT00976274

Keywords: Panax ginseng; Metabolic Syndrome; Randomized Controlled Trial

Received: February 6, 2012, Accepted: June 12, 2012

${ }^{*}$ Corresponding Author: Jae-Yong Shim

Tel: 82-2-2019-3480, Fax: 82-2-3463-3287

E-mail: hope@yuhs.ac

Korean Journal of Family Medicine

Copyright (C) 2012 The Korean Academy of Family Medicine

(a) This is an open-access article distributed under the terms of the Creative Commons Attribution Non-Commercial License (http://creativecommons.org/licenses/by-nc/3.0) which permits unrestricted noncommercial use, distribution, and reproduction in any medium, provided the original work is properly cited.

\section{INTRODUCTION}

Metabolic syndrome represents a cluster of cardiometabolic risk factors, including central obesity, elevated blood pressure, impaired glucose metabolism, and atherogenic dyslipidemia. The prevalence of metabolic syndrome is currently reaching epidemic proportions throughout the world. Subjects with metabolic syndrome are more susceptible to type 2 diabetes, ${ }^{1)}$ cardiovascular disease (CVD), ${ }^{1)}$ and some cancers, ${ }^{2)}$ which are major leading causes of death, especially in developed countries. 
Panax ginseng has been used to promote general health and treat illness in traditional oriental medicine. Particularly, Korean red ginseng (KRG) has been reported to have various beneficial effects on vascular health, energy metabolism, pain-relief, and cancer prevention. ${ }^{3)}$ Many animal studies have shown that KRG has potential benefits on cardiovascular disease and several metabolic parameters, ${ }^{4-8)}$ but human studies have not provided consistent evidence yet. ${ }^{9-14)}$ Moreover, although most human studies have been conducted in patients with individual diseases, such as hypertension, diabetes, and hyperlipidemia, little is known about the effects of KRG on cardiovascular risks in subjects with metabolic syndrome.

The aim of this double-blind, placebo-controlled, randomized study was to investigate the effects of KRG on cardiovascular risks in subjects with metabolic syndrome, including blood pressure, fasting plasma glucose, insulin sensitivity, lipid profile, oxidized low density lipoprotein (LDL) level, and arterial stiffness.

\section{METHODS}

\section{Study Subjects}

A single-center, double-blind, placebo-controlled, randomized clinical trial was designed. The study was approved by the institutional review board (IRB) of Gangnam Severance Hospital, Yonsei University College of Medicine in Seoul, Korea (IRB no. 3-2009-0015). The study complied with the code of ethics of the World Medical Association (Declaration of Helsinki) with all subjects giving informed consent before participation.

Study subjects were older than 20 years of age, presented with metabolic syndrome, and were recruited by advertisement from August 2009 to December 2010. The modified National Cholesterol Education Program Adult Treatment Panel III was used for the definition of metabolic syndrome. ${ }^{15)}$ Metabolic syndrome was defined by the presence of 3 or more of the following risk factors: 1) waist circumference $\geq 90 \mathrm{~cm}$ for men and $\geq 80 \mathrm{~cm}$ for women, 2) high triglyceride $\geq 150 \mathrm{mg} / \mathrm{dL}, 3$ ) low high density lipoprotein (HDL) cholesterol $<40 \mathrm{mg} / \mathrm{dL}$ for men and $<50$ $\mathrm{mg} / \mathrm{dL}$ for women, 4) elevated systolic blood pressure $\geq 130 \mathrm{~mm}$ $\mathrm{Hg}$ or elevated diastolic blood pressure $\geq 85 \mathrm{~mm} \mathrm{Hg}$, and 5) high fasting plasma glucose $\geq 100 \mathrm{mg} / \mathrm{dL}$ based on the revised American Diabetes Association criteria. ${ }^{16)}$ Subjects were excluded if they were taking drugs that could affect metabolic and vascular functions, including blood pressure-lowering drugs, anti-diabetic drugs, and lipid-lowering drugs, had uncontrolled hypertension (systolic blood pressure $\geq 160 \mathrm{~mm} \mathrm{Hg}$ or diastolic blood pressure $\geq 100$ $\mathrm{mm} \mathrm{Hg}$ ), fasting blood sugar $\geq 126 \mathrm{mg} / \mathrm{dL}$, hyperlipidemia (triglycerides $\geq 400 \mathrm{mg} / \mathrm{dL}$ or total cholesterol $\geq 250 \mathrm{mg} / \mathrm{dL}$ ), or a history of cardiovascular disease. After the initial screening visit, subjects were randomly assigned in a double-blind fashion to receive either $1.5 \mathrm{~g}$ of KRG (KRG powder capsule; Korea Ginseng Co., Seoul, Korea) or identical-appearing placebo with ginseng flavor three times a day for 12 weeks. Randomization was done according to computer-generated random number sequence. KRG was prepared from roots of a 6-year-old fresh Panax ginseng C.A. Meyer, which were harvested in Korea. Red ginseng was made by steaming fresh ginseng at $90^{\circ} \mathrm{C}$ to $100^{\circ} \mathrm{C}$ for 3 hours and then drying at $50^{\circ} \mathrm{C}$ to $80^{\circ} \mathrm{C}$. A voucher specimen was deposited at the Korea Ginseng Corporation. KRG was analyzed by high-performance liquid chromatography. KRG contained major ginsenoside-Rg1: $2.89 \%$, Re: $2.16 \%$, Rf: 0.93\%, Rh1: 0.13\%, Rg2: 0.58\%, Rb1: 5.16\%, Rc: $2.22 \%$, Rb2: $1.82 \%$, Rd: $0.47 \%$, Rg3: $0.22 \%$, and other minor ginsenosides.

\section{Measurements}

We collected anthropometric measurements, blood for laboratory testing, and brachial-ankle pulse wave velocity (baPWV) at the initial (week 0) and final (week 12) visits (Figure 1). Past medical history, health-related behaviors (smoking, alcohol intake, and regular exercise), and anthropometric measurements were obtained through a structured history review and a physical examination. Body weight and height were measured while the subject was wearing light indoor clothing without shoes and were rounded to the nearest $0.1 \mathrm{~kg}$ and $0.1 \mathrm{~cm}$, respectively. Body mass index was calculated as the ratio of weight $(\mathrm{kg}) /$ height $\left(\mathrm{m}^{2}\right)$. Blood pressure was measured in the right arm using a standard mercury sphygmomanometer (Baumanometer; WA Baum Co., Copiague, NY, USA). After a 12-hour overnight fast, blood samples were obtained from the antecubital veins. Specimens were centrifuged, and the serum was immediately frozen at $-80^{\circ} \mathrm{C}$. Leukocyte counts were quantified by an automated blood cell counter (ADVIA 120; Bayer, Tarrytown, NY, USA). Serum levels of blood glucose, insulin, high-sensitivity C-reactive protein (CRP), total cholesterol, HDL-cholesterol, and triglyceride 


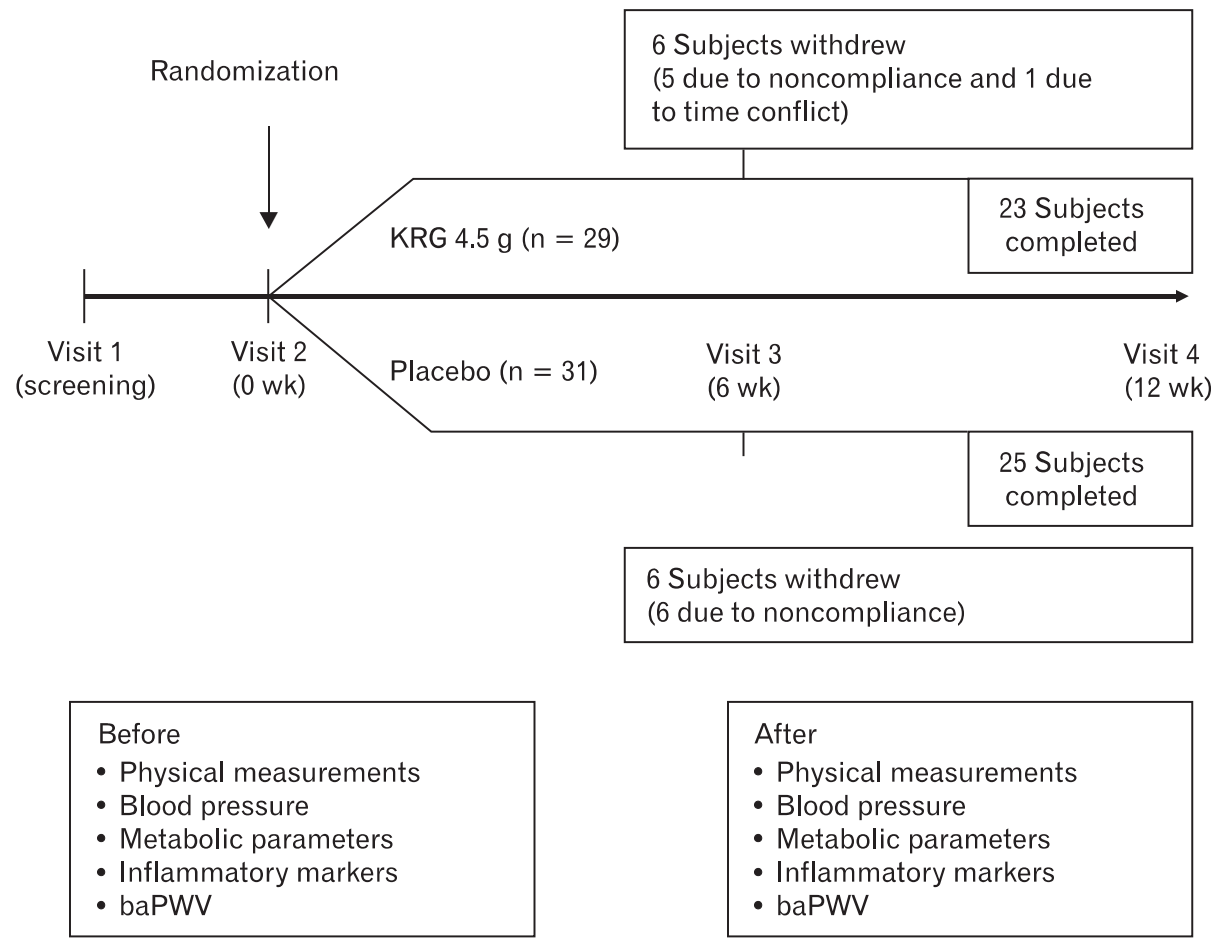

Figure 1. Flowchart of the study design and subject participation. KRG: Korean red ginseng, baPWV: brachial-ankle pulse wave velocity. were assayed enzymatically (Bayer) using an ADVIA 1650 autoanalyzer (Bayer). Insulin resistance was estimated using the homeostatic model assessment of insulin resistance (HOMA-IR) with the following equation: HOMA-IR = (fasting insulin $[\mu \mathrm{IU} /$ $\mathrm{mL}] \times$ fasting plasma glucose $[\mathrm{mg} / \mathrm{dL}] / 405)$. Oxidized LDLcholesterol was measured using an electrochemiluminescence immunoassay with the Mercodia Oxidized LDL Competitive ELISA test (Mercodia, Uppsala, Sweden), a solid-phase enzyme immunoassay modified from the original method of Holvoet et al. ${ }^{17)}$ During incubation, oxidized LDL in the sample competes with a fixed amount of oxidized LDL bound to the microtiter wells for binding of biotin-labeled specific antibodies (mAb-4E6).

Arterial stiffness was measured via baPWV using a volumeplethysmographic apparatus (PWV/ABI; Colin Co., Komaki, Japan). The coefficients of variation were $8.4 \%$ for interobserver reproducibility and $10.0 \%$ for intraobserver reproducibility.

\section{Sample Size Estimation}

The intended sample of 60 recruited subjects provided a power of approximately $80 \%$, assuming a significance level $<0.05$, to detect a $9.5 \mathrm{~mm} \mathrm{Hg}$ placebo-adjusted treatment effect in systolic blood pressure (change from baseline to week 12) with a standard deviation of $11.5 \mathrm{~mm} \mathrm{Hg}$. The drop-out rate was expected to be less than $20 \%$, based on the documented good tolerability of nutraceutical combination. The formula for the sample size was as follows: $\mathrm{n}=2\left(\mathrm{z}_{\alpha / 2}+\mathrm{z}_{\beta}\right)^{2} /\left\{\left(\mu_{0}-\mu_{1}\right) /\right.$ $\sigma\}^{2} ; \alpha=0.05, \beta=0.20$, two population means $\left(\mu_{0}\right.$ and $\left.\mu_{1}\right), \sigma^{2}=$ common variance.

\section{Statistical Analysis}

Data are presented as mean \pm SD. The primary outcome (blood pressure and arterial stiffness) and the secondary outcome (metabolic and inflammatory markers) were used to compare the KRG group to the placebo group. The Wilcoxon signedrank test was used to calculate the significances of the differences from baseline in each group. The effects of treatment relative to the control levels were analyzed by comparing the changes from baseline between the two treatment arms using Wilcoxon ranksum test. All analyses were conducted using SAS ver. 9.1 (SAS Inc., Cary, NC, USA). All statistical tests were two-sided, and a P $<0.05$ was considered significant. 
Table 1. Clinical characteristics of the subjects at baseline.

\begin{tabular}{|c|c|c|c|}
\hline & Ginseng group $(\mathrm{n}=29)$ & Placebo group $(\mathrm{n}=31)$ & P-value* \\
\hline Female & $9(31.0)$ & $12(38.7)$ & 0.533 \\
\hline Age (yr) & $43.1 \pm 10.6$ & $46.2 \pm 11.0$ & 0.263 \\
\hline Waist circumference $(\mathrm{cm})$ & $95.7 \pm 9.0$ & $91.8 \pm 7.7$ & 0.069 \\
\hline Systolic blood pressure (mm Hg) & $134.4 \pm 11.2$ & $131.6 \pm 10.8$ & 0.316 \\
\hline Diastolic blood pressure (mm Hg) & $85.7 \pm 8.8$ & $85.7 \pm 8.3$ & 0.971 \\
\hline Total cholesterol (mg/dL) & $193.2 \pm 41.6$ & $192.0 \pm 26.8$ & 0.898 \\
\hline High density lipoprotein cholesterol (mg/dL) & $44.1 \pm 11.6$ & $42.3 \pm 8.4$ & 0.472 \\
\hline Triglyceride (mg/dL) & $163.9 \pm 94.4$ & $207.5 \pm 210.5$ & 0.301 \\
\hline Oxidized low density lipoprotein $(\mu \mathrm{IU} / \mathrm{mL})$ & $88.8 \pm 40.2$ & $81.5 \pm 32.3$ & 0.445 \\
\hline Fasting plasma glucose (mg/dL) & $106.7 \pm 18.8$ & $116.4 \pm 65.9$ & 0.437 \\
\hline Insulin $(\mu \mathrm{IU} / \mathrm{mL})$ & $11.1 \pm 8.7$ & $9.9 \pm 10.3$ & 0.626 \\
\hline Homeostasis model assessment of insulin resistance & $3.1 \pm 2.9$ & $3.1 \pm 4.2$ & 0.989 \\
\hline C-reactive protein (mg/L) & $2.0 \pm 2.0$ & $2.0 \pm 2.4$ & 0.941 \\
\hline White blood cell count $\left(10^{3}\right.$ cells $\left./ \mu \mathrm{L}\right)$ & $7.05 \pm 2.22$ & $6.28 \pm 1.32$ & 0.115 \\
\hline Brachial-ankle pulse wave velocity $(\mathrm{cm} / \mathrm{s})$ & $1,288 \pm 150$ & $1,323 \pm 162$ & 0.392 \\
\hline Current smoker & $11(37.9)$ & $8(25.8)$ & 0.122 \\
\hline Alcohol ingestion $^{\dagger}$ & $12(41.4)$ & $10(32.3)$ & 0.463 \\
\hline Physical activity $^{\ddagger}$ & $13(44.8)$ & $8(25.8)$ & 0.122 \\
\hline
\end{tabular}

Values are presented as mean \pm SD or number (\%).

${ }^{*}$ P-values were calculated with $\mathrm{t}$-test or chi-square test. ${ }^{\dagger}$ Alcohol drinking $\geq 140 \mathrm{~g} / \mathrm{wk}$. ${ }^{\ddagger}$ Regular exercise $\geq$ twice/wk.

\section{RESULTS}

The study criteria were met by 60 subjects who were randomized for participation. We defined good compliance as taking more than $80 \%$ of the pills given to the participants. Of these, 12 subjects withdrew ( 11 due to noncompliance and 1 due to time conflicts) and 48 subjects completed the study (KRG group, $\mathrm{n}=23$; placebo group, $\mathrm{n}=25$ ) (Figure 1). According to the self-reported questionnaire, one subject reported gastrointestinal disturbance after placebo administration, whereas there were no reported adverse reactions to $\mathrm{KRG}$ administration.

Baseline characteristics of all subjects are presented in Table 1. The following parameters were similar in both the KRG and placebo group: age, waist circumference, systolic blood pressure, diastolic blood pressure, fasting plasma glucose, total cholesterol, HDL-cholesterol, triglyceride, insulin, oxidized LDL, CRP, leukocyte count, and baPWV. Table 2 summarizes the interand intra-group differences in metabolic parameters, arterial stiffness, and inflammatory markers. Mean waist circumference and systolic blood pressure decreased significantly in the KRG group $(\mathrm{P}=0.015$ and $\mathrm{P}=0.038$, respectively $)$ and mean HDLcholesterol increased in the KRG group $(P=0.019)$. Mean systolic blood pressure and diastolic blood pressure decreased in the placebo group $(\mathrm{P}<0.001$ and $\mathrm{P}<0.001$, respectively). However, the extent of change in waist circumference, blood pressure, and HDL-cholesterol between the KRG and placebo groups was not significantly different. Oral administration of KRG did not significantly affect blood pressure; inflammatory markers, including oxidized LDL, CRP, and leukocyte count; or baPWV. 
Table 2. Changes in the laboratory values after the administration of the ginseng or placebo for 12 weeks.

\begin{tabular}{|c|c|c|c|c|c|c|c|}
\hline & \multicolumn{3}{|c|}{ Ginseng group $(\mathrm{n}=23)$} & \multicolumn{3}{|c|}{ Placebo group $(\mathrm{n}=25)$} & \multirow{2}{*}{ P-value } \\
\hline & Before & $\Delta^{*}$ & P-value* & Before & $\Delta$ & P-value ${ }^{\dagger}$ & \\
\hline Waist circumference $(\mathrm{cm})$ & $94.7 \pm 8.2$ & $-2.4 \pm 4.3$ & 0.015 & $90.5 \pm 6.8$ & $-0.8 \pm 4.7$ & 0.268 & 0.226 \\
\hline Systolic blood pressure (mm Hg) & $134.5 \pm 12.0$ & $-7.0 \pm 15.0$ & 0.038 & $129.3 \pm 10.5$ & $-6.8 \pm 7.6$ & $<0.001$ & 0.917 \\
\hline Diastolic blood pressure $(\mathrm{mm} \mathrm{Hg})$ & $85.6 \pm 9.7$ & $-3.5 \pm 8.5$ & 0.094 & $83.8 \pm 8.0$ & $-4.2 \pm 5.5$ & $<0.001$ & 0.717 \\
\hline Total cholesterol (mg/dL) & $189.9 \pm 39.4$ & $4.2 \pm 16.3$ & 0.283 & $191.2 \pm 26.6$ & $1.2 \pm 24.3$ & 0.771 & 0.342 \\
\hline HDL cholesterol (mg/dL) & $43.3 \pm 10.1$ & $3.0 \pm 8.2$ & 0.019 & $41.9 \pm 8.3$ & $0.6 \pm 6.4$ & 0.374 & 0.268 \\
\hline Triglyceride (mg/dL) & $163.6 \pm 99.5$ & $5.1 \pm 75.0$ & 0.694 & $204.6 \pm 227.9$ & $-28.4 \pm 136.3$ & 0.972 & 0.764 \\
\hline Oxidized LDL ( $\mu \mathrm{IU} / \mathrm{mL})$ & $79.5 \pm 35.9$ & $-5.1 \pm 40.9$ & 0.621 & $83.0 \pm 35.2$ & $2.5 \pm 51.7$ & 0.836 & 0.687 \\
\hline Fasting plasma glucose (mg/dL) & $107.0 \pm 19.9$ & $3.4 \pm 17.2$ & 0.941 & $105.5 \pm 12.5$ & $0.9 \pm 11.0$ & 0.734 & 0.942 \\
\hline Insulin $(\mu \mathrm{IU} / \mathrm{mL})$ & $10.9 \pm 8.3$ & $1.2 \pm 18.7$ & 0.153 & $10.4 \pm 11.3$ & $-2.7 \pm 9.3$ & 0.123 & 0.679 \\
\hline HOMA-IR & $3.1 \pm 3.0$ & $0.9 \pm 7.7$ & 0.365 & $2.8 \pm 3.4$ & $-0.7 \pm 2.9$ & 0.322 & 0.772 \\
\hline C-reactive protein $(\mathrm{mg} / \mathrm{L})$ & $2.1 \pm 2.1$ & $-0.4 \pm 2.1$ & 0.219 & $2.0 \pm 2.5$ & $-0.1 \pm 2.9$ & 0.671 & 0.515 \\
\hline WBC count $\left(10^{3}\right.$ cells $\left./ \mu \mathrm{L}\right)$ & $7.0 \pm 2.1$ & $-0.4 \pm 1.6$ & 0.441 & $6.4 \pm 1.4$ & $0.1 \pm 1.4$ & 0.896 & 0.451 \\
\hline $\mathrm{baPWV}(\mathrm{cm} / \mathrm{s})$ & $1,272 \pm 155$ & $-11.9 \pm 113.8$ & 0.477 & $1,289 \pm 153$ & $27.1 \pm 122.8$ & 0.306 & 0.259 \\
\hline
\end{tabular}

HDL: high density lipoprotein, LDL: low density lipoprotein, HOMA-IR: homeostasis model assessment for insulin resistance, WBC: white blood cell, baPWV: brachial-ankle pulse wave velocity.

${ }^{*} \Delta$ : change after 12 weeks. ${ }^{\dagger} \mathrm{P}$-value was calculated by Wilcoxon signed-rank test for within-treatment differences. ${ }^{*} \mathrm{P}$-value was calculated by Wilcoxon rank-sum test for between-treatment differences.

\section{DISCUSSION}

In this double-blind, randomized, and placebo-controlled study, there was no significant improvement in metabolic parameters, oxidative or inflammatory markers, or baPWV after oral administration of KRG compared to the placebo group.

Central obesity is a core characteristic of metabolic syndrome. Increased visceral adipose tissues are accompanied by chronic low grade inflammation and insulin resistance, which explains various features of metabolic syndrome. Adipose tissue is now accepted as an endocrine organ that secretes a variety of adipokines and cytokines. Thus, metabolic syndrome is implicated by an increased production of proinflammatory cytokines, such as interleukin- 6 and tumor necrosis factor- $\alpha{ }^{18,19)}$ These cytokines play a key role in regulating the vessel wall tone by affecting the release of nitric oxide and endothelin-1 in the subendothelial space. ${ }^{20,21)}$ This cascade may cause endothelial dysfunction and alter arterial elastic properties, leading to increased blood pressure and structural stiffness. KRG has several constituents with curable properties, of which ginsenosides have been noticed to be a major pharmacologic component. In animal studies and an in vitro study using human umbilical vein endothelial cell, ${ }^{22-24)}$ ginsenosides relax blood vessels and improve blood flow through nitric oxide release by activating endothelial nitric oxide synthase. Human clinical trials have demonstrated that KRG has favorable effects on blood pressure, and the study included a range of subjects, from those in good health to patients with congestive heart failure, but the majority of patients did not demonstrate a significant change in response to KRG administration. ${ }^{25)}$ Han et al. ${ }^{10)}$ reported that red ginseng significantly decreased systolic blood pressure in essential hypertension patients without antihypertensive medication. Some studies have reported that ginseng slightly increased blood pressure, ${ }^{9,26)}$ but the study was conducted in healthy subjects. Therefore, there was a possibility that KRG's effects vary according to baseline blood pressure. We excluded subjects who were currently taking drugs that could modify metabolic and vascular function parameters, and patients in need of medical treatment. This may have resulted in a study population with relatively early metabolic syndrome that 
attenuated the favorable effects of KRG.

KRG has also been reported to improve insulin resistance and have anti-hyperlipidemic effects. ${ }^{7,11,27)}$ Furthermore, some studies have indicated that KRG might reduce weight gain. ${ }^{28,29)}$ Although the reason for favorable energy metabolism of KRG is unclear, it may be explained by activation of adenosine monophosphateactivated protein kinase ${ }^{29)}$ and reductions in food intake or appetite. ${ }^{30)}$ However, firm evidence is still lacking in clinical trials. ${ }^{25)}$

The lack of beneficial effects for KRG in this study has several possible explanations. First, we could not fully control participants' lifestyle such as exercise and diet. Although all participants were instructed to exercise on a regular basis and mildly reduce their calorie intake, each individual's compliance may have been different. Second, the relationship between KRG dosage and its effect on CVD risks was not evaluated. Further research is warranted to clarify the influence of a dose-effect relationship to determine the optimum dosage in subjects with metabolic syndrome. Third, the ginsenoside Rg3 has been known to improve insulin sensitivity, ${ }^{31)}$ but the $0.22 \%$ of $\mathrm{Rg} 3$ used in this study may be too low to be expected to have any beneficial effects on metabolic parameters. Lastly, gender differences were not considered. Further investigation is warranted to better understand gender differences in the cardiovascular effects of KRG in subjects with metabolic syndrome.

In conclusion, we found no evidence that KRG had an effect on blood pressure, lipid profile, oxidized LDL, fasting blood glucose, or arterial stiffness in subjects with metabolic syndrome. These findings warrant further longer-term prospective clinical investigations with a larger population.

\section{CONFLICT OF INTEREST}

No potential conflict of interest relevant to this article was reported.

\section{ACKNOWLEDGMENTS}

This work was supported by a grant from the Korean Society of Ginseng and funded by the Korean Ginseng Cooperation.

\section{REFERENCES}

1. Wilson PW, D’Agostino RB, Parise H, Sullivan L, Meigs JB. Metabolic syndrome as a precursor of cardiovascular disease and type 2 diabetes mellitus. Circulation 2005;112:3066-72.

2. Russo A, Autelitano M, Bisanti L. Metabolic syndrome and cancer risk. Eur J Cancer 2008;44:293-7.

3. Jung NP, Jin SH. Studies on the physiological and biochemical effects of Korean ginseng. Korean J Ginseng Sci 1996;20:431-71.

4. Hah JS, Kang BS, Kang DH. Effect of Panax ginseng alcohol extract on cardiovascular system. Yonsei Med J 1978;19:11-8.

5. Jeon BH, Kim CS, Park KS, Lee JW, Park JB, Kim KJ, et al. Effect of Korea red ginseng on the blood pressure in conscious hypertensive rats. Gen Pharmacol 2000;35:13541.

6. Yun SN, Ko SK, Lee KH, Chung SH. Vinegar-processed ginseng radix improves metabolic syndrome induced by a high fat diet in ICR mice. Arch Pharm Res 2007;30:587-95.

7. Kim K, Kim HY. Korean red ginseng stimulates insulin release from isolated rat pancreatic islets. J Ethnopharmacol $2008 ; 120: 190-5$

8. Joo NS. Various effect of Korean ginseng. Korean J Fam Med 2010;31:895-6.

9. Caron MF, Hotsko AL, Robertson S, Mandybur L, Kluger J, White CM. Electrocardiographic and hemodynamic effects of Panax ginseng. Ann Pharmacother 2002;36:758-63.

10. Han KH, Choe SC, Kim HS, Sohn DW, Nam KY, Oh BH, et al. Effect of red ginseng on blood pressure in patients with essential hypertension and white coat hypertension. Am J Chin Med 1998;26:199-209.

11. Kim SH, Park KS. Effects of Panax ginseng extract on lipid metabolism in humans. Pharmacol Res 2003;48:511-3.

12. Kim HS, Lee BM. Protective effects of antioxidant supplementation on plasma lipid peroxidation in smokers. J Toxicol Environ Health A 2001;63:583-98.

13. Sievenpiper JL, Arnason JT, Leiter LA, Vuksan V. Null and opposing effects of Asian ginseng (Panax ginseng C.A. Meyer) on acute glycemia: results of two acute dose escalation studies. J Am Coll Nutr 2003;22:524-32.

14. Vuksan V, Sievenpiper JL, Wong J, Xu Z, Beljan-Zdravkovic 
$\mathrm{U}$, Arnason JT, et al. American ginseng (Panax quinquefolius

L.) attenuates postprandial glycemia in a time-dependent but not dose-dependent manner in healthy individuals. Am J Clin Nutr 2001;73:753-8.

15. Expert Panel on Detection, Evaluation, and Treatment of High Blood Cholesterol in Adults. Executive Summary of The Third Report of The National Cholesterol Education Program (NCEP) Expert Panel on Detection, Evaluation, And Treatment of High Blood Cholesterol In Adults (Adult Treatment Panel III). JAMA 2001;285:2486-97.

16. Genuth S, Alberti KG, Bennett P, Buse J, Defronzo R, Kahn R, et al. Follow-up report on the diagnosis of diabetes mellitus. Diabetes Care 2003;26:3160-7.

17. Holvoet P, Lee DH, Steffes M, Gross M, Jacobs DR Jr. Association between circulating oxidized low-density lipoprotein and incidence of the metabolic syndrome. JAMA 2008;299:2287-93.

18. Despres JP, Lemieux I, Bergeron J, Pibarot P, Mathieu P, Larose E, et al. Abdominal obesity and the metabolic syndrome: contribution to global cardiometabolic risk. Arterioscler Thromb Vasc Biol 2008;28:1039-49.

19. Wisse BE. The inflammatory syndrome: the role of adipose tissue cytokines in metabolic disorders linked to obesity. J Am Soc Nephrol 2004; 15:2792-800.

20. Kahaleh MB, Fan PS. Effect of cytokines on the production of endothelin by endothelial cells. Clin Exp Rheumatol 1997; 15:163-7.

21. Bhagat K, Vallance P. Effects of cytokines on nitric oxide pathways in human vasculature. Curr Opin Nephrol Hypertens 1999;8:89-96.

22. Kang SY, Kim ND. The antihypertensive effect of red ginseng saponin and the endothelium-derived vascular relaxation. Korean J Ginseng Sci 1992;16:175-82.
23. Kim ND, Kang SY, Schini VB. Ginsenosides evoke endotheliumdependent vascular relaxation in rat aorta. Gen Pharmacol 1994;25:1071-7.

24. Leung KW, Cheng YK, Mak NK, Chan KK, Fan TP, Wong RN. Signaling pathway of ginsenoside-Rg1 leading to nitric oxide production in endothelial cells. FEBS Lett 2006;580: 3211-6.

25. Buettner C, Yeh GY, Phillips RS, Mittleman MA, Kaptchuk TJ. Systematic review of the effects of ginseng on cardiovascular risk factors. Ann Pharmacother 2006;40:8395.

26. Cherdrungsi P, Rungroeng K. Effect of standardized ginseng extract and exercise training on aerobic and anaerobic exercise capacities in humans. Korean J Ginseng Sci 1995; 19:93-100.

27. Luo JZ, Luo L. Ginseng on hyperglycemia: effects and mechanisms. Evid Based Complement Alternat Med 2009;6: 423-7.

28. Karu N, Reifen R, Kerem Z. Weight gain reduction in mice fed Panax ginseng saponin, a pancreatic lipase inhibitor. J Agric Food Chem 2007;55:2824-8.

29. Lee HJ, Lee YH, Park SK, Kang ES, Kim HJ, Lee YC, et al. Korean red ginseng (Panax ginseng) improves insulin sensitivity and attenuates the development of diabetes in Otsuka Long-Evans Tokushima fatty rats. Metabolism 2009; 58:1170-7.

30. Hasani-Ranjbar S, Nayebi N, Larijani B, Abdollahi M. A systematic review of the efficacy and safety of herbal medicines used in the treatment of obesity. World J Gastroenterol 2009;15:3073-85.

31. Kim M, Ahn BY, Lee JS, Chung SS, Lim S, Park SG, et al. The ginsenoside Rg3 has a stimulatory effect on insulin signaling in L6 myotubes. Biochem Biophys Res Commun 2009;389: 70-3. 